\title{
Willingness to Pay for Offsetting Carbon Programs by Vehicle Owners in Sunsari District, Nepal
}

\author{
Lok Raj Nepal ${ }^{1}$ and Dr. Shi Juan ${ }^{2}$ \\ Corresponding author: Lok Raj Nepal \\ Email: lok_nepal@hotmail.com
}

\begin{abstract}
:
The objective of this study was to assess the willingness to pay (WTP) of vehicle owners for carbon offsetting programs. This study could potentially assist local governmental institutions to take further steps in environmental conservation programs. A contingent valuation method was used. Open-ended questionnaire surveys were conducted with 181 respondents. The results revealed that WTP was dependent on several demographic variables including educational level, occupation, gender, and residential area. However, only occupation and educational level significantly affected the WTP of the respondents. The total WTP was 600 NRs.
\end{abstract}

Key Words: WTP, Community forest, Carbon offsetting programs, Kyoto Protocol, REDD

\section{Introduction}

The 1992 Earth Summit raised socio-political awareness of climate change and its potentially adverse effects. The Kyoto Protocol of the United Nations Framework Conventions on Climate Change is a treaty whereby industrialized countries commit to reducing greenhouse gases within a period of four years. Three programs were developed during the first phase of the Kyoto Protocol: the International Emission Trading (IET) program, the Clean Development Mechanism (CDM) program, and the Joint Implementation (JI) program. IET and JI were developed for developed countries to reduce emissions through emission trading quotas. CDM was developed for developing countries to reduce emissions through carbon dioxide sequestration. With the Kyoto Protocol, several voluntary emission reduction programs have been developed in Europe and other developed countries.

Community-based forestry regimes have restored denuded landscape and created opportunities to produce diverse forest products and services for several stakeholders groups, including in local and international communities. The 2007 Bali Action Plan allowed developing countries such as Nepal to participate in forest carbon financing opportunities

${ }^{1}$ MSc. Student, Forestry College, Beijing Forestry University, P.O. Box 113, 100083, Beijing, China

2 Dr Shi Juan, Associate Professor, Beijing Forestry University, Beijing, China, E-mail: shi_juan@263.net 
through the reduction of emissions from deforestation and forest degradation. However, there are many issues that need to be addressed, including the number of individuals who depend on forest for their livelihoods. Community forestry reduces deforestation and degradation in the Himalaya region of Nepal.

From a climate perspective, community forestry has contributed to enhancing natural sink capacity. Voluntary carbon offsetting programs provide further incentives for sustainability strategies. In voluntary carbon offsetting programs, environmentally-conscious individuals and governments compensate for their greenhouse gas emissions by purchasing carbon credits from offset providers. Offset providers subsequently invest in carbon emission reduction projects. In Nepal, the condition of the forests, especially in hill areas, is improving. However, local people do not obtain significant benefits from purchasing carbon credits. Voluntary carbon offsetting programs should therefore be more effective in allowing public participation in sustainable forest management. Certain changes should be implemented in the voluntary carbon offsetting programs whereby wealthier people, who contribute to carbon emissions, pay for those individuals who are environmentally-conscious and aim to conserve the environment.

The purpose of the study is to encourage local governments to initiate programs that ensure benefits for individuals and communities that conserve forests. A hypothetical scenario was developed whereby in the near future the municipality of Dharan announces carbon offsetting programs that can reduce and offset gas emissions. Based on the program, the municipality of Dharan requests a monetary contribution from vehicle owners, who supposedly contribute more carbon emissions than non-vehicle owners. The willingness to pay (WTP) and contribute to carbon offsetting programs was evaluated in a group of vehicle owners. The results of this study may assist local governments in the implementation of local carbon offsetting programs that provide benefits to the local community forest and help in the protection of the environment.

\section{Materials and Methods}

\section{Contingent valuation method}

A contingent valuation method (CVM) is defined as a "stated preference method". The CVM is a method that allows individuals to tell researchers directly and through surveys what they are willing to pay for environmental services and/or improvements including potable water services (use value) and biodiversity and carbon offsetting programs (non-used value). A survey was designed to facilitate face-to-face interviews to assess the WTP from respondents. CVM relies on referendum formats using the dichotomous-choice method and the bidding game approach. The dichotomous-choice method tends to overestimate WTP, especially in low income countries. Additionally, obtaining statistically reliable results from a dichotomous-choice survey requires a very large sample size. Therefore, an openended questionnaire survey, which is the most common and simplest CVM format, was used to assess WTP. 


\section{Questionnaire design}

Questionnaire design is the first and most important step; an effectively designed questionnaire can provide useful information on WTP. In the design of the questionnaire, three major points were taken into consideration: the questionnaires consistently gathered the same type of information, were provided by experts on the subject, and were easy to understand by the average respondent. Experienced researchers were consulted prior to conducting the surveys to improve questionnaire design, provide understandable description of carbon offsetting services, and allow feedback from the respondents. The questionnaire had six sections (Carson et al, 2001):

- $\quad$ The first section introduced the purpose of the survey.

- $\quad$ The second section provided a clear and detailed description of the valued good. It also included a section where the surveyor recorded the attitudes of the respondents towards the valued good.

- The third section introduced the contingent valuation scenario. It also included the current or baseline situation (i.e., status quo) and possible future natural resources in the case that the proposed policy was not implemented. This included the institutional context in which the valued good was going to be provided and the form of payment.

- $\quad$ The fourth section, i.e., the elicitation section, asked the respondents for their maximum WTP to obtain the valued good and for their minimum WTA for giving up the valued good.

- $\quad$ The fifth section asked the respondents to verify the answers provided.

- The sixth and last section was devoted to debriefing questions on the socio-demographic characteristics of the respondents.

\section{Survey administration}

The method by which surveys are administered constitutes another important step. Survey administration is performed on the basis of the population, survey mode, sampling approach, and sample size. Public surveys may be performed through several methods, e.g., mail, telephone, in person (i.e., face-to-face interviews), or internet. Face-to-face interviews were chosen because the other methods were not practical for the purposes of this study.

A random sampling approach was used to select the respondents. In the city, surveyors looked for parked vehicles and interviewed the vehicle owners. Sample stratification is usually performed with sample clustering based on age or gender. However, in this study the parked vehicles were chosen and sample stratification was performed while analysing the data.

The interviews were conducted during the evenings of work weeks so that individuals were not in a rush. During the holidays, interviews were conducted during the day. On average, each interview lasted approximately 15-20 minutes. 


\section{Result and Discussion}

This study was conducted to assess the WTP by vehicle owners for carbon offsetting programs using a CVM. This method can sometimes overestimate results. Carbon offsetting programs might be developed in the municipality of Dharan in the future. This study, which consisted on a hypothetical scenario to assess WTP, was therefore conducted in the municipality of Dharan. A summary of the socio-economic and demographic characteristics of the respondents is shown below.

Table 1: Socio-demographic characteristics of the respondents

\begin{tabular}{|c|c|c|c|c|c|c|c|}
\hline S.N. & $\begin{array}{c}\text { Respondent } \\
\text { characteristics }\end{array}$ & Number & $\%$ & S.N. & Variables & Number & $\%$ \\
\hline 1 & Number & 181 & & \multirow[t]{4}{*}{4} & Residential area & & \\
\hline \multirow[t]{6}{*}{2} & Age (y) & & & & Sunsari district & 109 & 60.2 \\
\hline & $<18$ & 0 & & & Adjoining districts & 46 & 25.4 \\
\hline & $18-30$ & 61 & 33.70 & & Other districts & 26 & 14.4 \\
\hline & $31-43$ & 61 & 33.70 & \multirow[t]{4}{*}{5} & Educational level & & \\
\hline & $44-56$ & 59 & 32.60 & & Secondary & 96 & 53 \\
\hline & $>56$ & 0 & & & Bachelor's degree & 58 & 32 \\
\hline \multirow[t]{5}{*}{3} & Gender & & & & Master's degree & 27 & 15 \\
\hline & Male & 141 & 77.9 & \multirow[t]{4}{*}{6} & Occupation & & \\
\hline & Female & 40 & 22.1 & & Business & 72 & 39.8 \\
\hline & & & & & Service & 71 & 39.2 \\
\hline & & & & & Student & 38 & 21 \\
\hline
\end{tabular}

In this study, 200 individuals were recruited. However, 19 individuals refused to respond to the questionnaires, thus 181 respondents participated in the survey. Each age group (i.e., $18-30,31-43$, and $44-56$ years of age) had approximately the same number of respondents (i.e., 33\%). The number of male respondents was $>80 \%$. More than $50 \%$ of the respondents lived close to the study site (i.e., Sunsari district). Other respondents (25\%) lived in nearby districts whereas $14 \%$ of the respondents came from other parts of the country for business or personal reasons.

Most of the respondents only had secondary education. Thirty two percent of the respondents had a bachelor's degree and fifteen percent of the respondents had a Master's degree. The survey was conducted with vehicle owners; thus most of the respondents were business men, followed by service personnel and students.

\section{Descriptive statistics}


In this study, male respondents had a higher WTP $(1,027 \pm 416)$ than female respondents $(860 \pm 380)$. The reason for this discrepancy could be attributed to certain demographic differences (e.g., education level and residential area). In general, WTP increased with educational level. In respondents with Master's and Bachelor's degrees, the WTP was 1,148 \pm 410 and 1,014 \pm 397 , respectively. Less educated respondents had the lowest WTP $(927 \pm$ 414). Business men expressed a higher WTP than service personnel or students. The mean WTP was 1,225 \pm 363 in business men, $872 \pm 395$ in service personnel, and $766 \pm 310$ in students.

The respondents who lived in the district where the study was conducted (i.e., Sunsari district) expressed the highest WTP. On the other hand, the lowest WTP was obtained from respondents who lived in other parts of the country. The average WTP was 1,013 \pm 414 from respondents from the Sunsari district, $996 \pm 428$ from respondents from nearby districts, and $885 \pm 383$ from respondents from other parts of the country.

\section{Multiple regression results}

A multiple regression model was used to assess the effects of the demographic characteristics (e.g., gender, residential area, educational level, and occupation) on the respondents' WTP. The demographic characteristics were the independent variables whereas WTP was the dependent variable. Assuming that $\mathrm{K}$ independent variables are related to the dependent variable, a multiple regression model can be represented by the following equation:

$Y=\beta_{o}+\beta_{1}^{\prime} x_{1}+\beta_{2}^{\prime} x_{2}+\beta_{3}^{\prime} x_{3}+\beta_{4}^{\prime} x_{4}+\ldots+\beta_{k}^{\prime} x_{k}+\varepsilon$

Where $\mathrm{Y}$ is the dependent variable; $\mathrm{x}_{1}, \mathrm{x}_{2}, \ldots, \mathrm{x}_{\mathrm{k}}$ are the independent variables; $\beta_{1}, \beta_{2}, \ldots, \beta_{k}$ are coefficients; and $\varepsilon$ is the error variable. In this study, the multiple regression model was the following:

$W T P=\beta_{o}+\beta_{1} \times$ gender $_{i}+\beta_{2} \times$ residential area $_{i}+\beta_{3} \times$ educational level $_{i}+\beta_{4} \times$ occupation $_{i}+\varepsilon$

A summary of the multiple regression model is shown in Table 2. The coefficient of determination, $\mathrm{R}^{2}$, was 0.259 . This means that $25.9 \%$ of the variation in $\mathrm{WTP}$ could be explained by the four independent variables, whereas $74.1 \%$ of the variation remained unexplained. The adjusted $\mathrm{R}^{2}$ means that $\mathrm{R}^{2}$ had been adjusted to take account the sample size and the number of independent variables. 
Table 2: Multiple regression model results

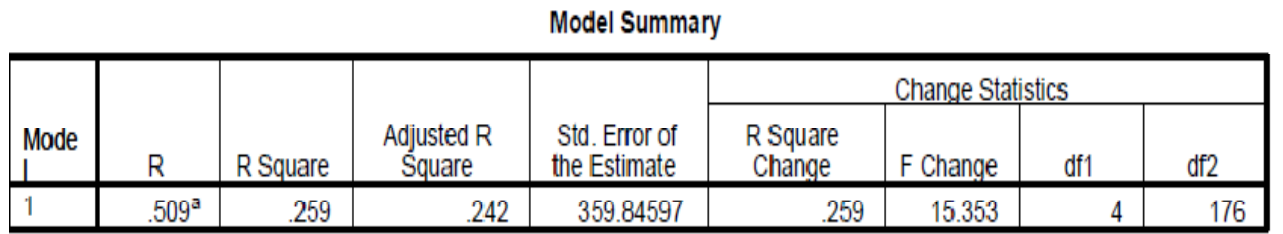

a. Predictors: (Constant), Sex, Education_status, Residence, Occupation

The coefficient of determination and the F-value were analysed to assess how the multiple regression model fit the data. The adjusted $\mathrm{R}^{2}$ was 0.242 , which implies that there was some variation in WTP. The variation in WTP could be explained by the multiple regression model equation. A small F-test value was indicative that most of the variation in WTP remained unexplained. The rejection region allowed us to determine whether the F-test value was large enough to reject the null hypothesis. In this study, the null and alternative hypotheses were:

$\mathrm{H}_{\mathrm{o}}: \beta_{1}=\beta_{2}=\ldots=\beta_{k}=0$

$\mathrm{H}_{\mathrm{A}}$ : At least one $\beta$ is not equal to zero

The test rejection region is where $\mathrm{F}>\mathrm{F}_{\alpha, \mathrm{K}, \mathrm{n}-\mathrm{k}-1}$ assuming $\alpha=0.05$. In this study, the F-test value was 15.352 and the F-critical value was 2.37 (at $\alpha=0.05$ ); thus, 15.352 (F-test value) > 2.37 (F-critical value). Therefore, the statistical analyses revealed that the multiple regression model was useful and that the independent variables should be included in the analysis of WTP because they have a significant effect on WTP.

Table 3: WTP coefficient

Coefficients ${ }^{3}$

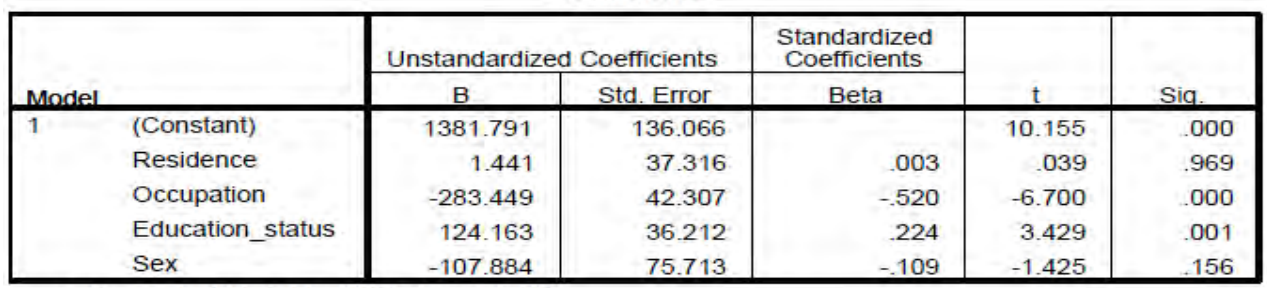

a. Dependent Variable: WTP_Amount_NRs

The coefficient of regression reveals the nature and magnitude of the relationship between the different independent variables. A positive coefficient of regression from the $t$-test is expected because the F-test value only explains the magnitude of the relationship between the variables. Based on the t-test, the intercept $\left(\beta_{\mathrm{o}}\right)$ was 1,381.71; this is the WTP value when the independent variables are equal to zero. 
The relationship between WTP and residential area was assessed by the coefficient $\beta_{1}$, which had a value of 1.44. Therefore, assuming that the other independent variables are held constant, the residential area variable increases WTP.

\section{Testing the coefficients}

There is more than one independent variable in a multiple regression model. We can test whether there is a linear relationship between each independent variable and the dependent variable. The null and alternative hypotheses in this study were:

$\mathrm{H}_{\mathrm{o}}: \beta_{i}=0$

$\mathrm{H}_{\mathrm{A}}: \beta_{i} \neq 0($ where $\mathrm{i}=1,2,3, \ldots, \mathrm{k})$

Based on the statistical analyses, $t$-test $=-6.70 \mathrm{t}$-critical $=1.65$ at $\alpha=0.05$ ); thus, $t$-test $>$ $\mathrm{t}$-critical. Therefore, the null hypothesis was rejected and we concluded that there was a significant effect of occupation on WTP. Furthermore, the $t$-test results revealed that educational level was significant at $p<0.05 ; t$-test (3.429) $>t$-critical (1.65). The null hypothesis was rejected and we concluded that there was a significant effect of educational level on WTP. The $p$-value of the two other independent variables (i.e., residential area and gender) was higher than 0.05; thus, the null hypothesis was not rejected. Both residential area and gender had no significant effects on WTP based on the multiple regression model.

In summary, an individual with high educational level and economic status would be more willing to pay a high amount of money to reduce carbon emissions and thus improve the environment. On the other hand, gender and residential area had no effect on WTP.

\section{WTP curve}

From the data, we created a WTP curve to reveal the percentage of respondents willing to pay for carbon offsetting programs. WTP ranged from 500 to 2,000 NRS. These amounts were divided into $16 \mathrm{WTP}$ points. The percentage of respondents falling into each of those 16 WTP points was calculated and plotted (Figure 1).

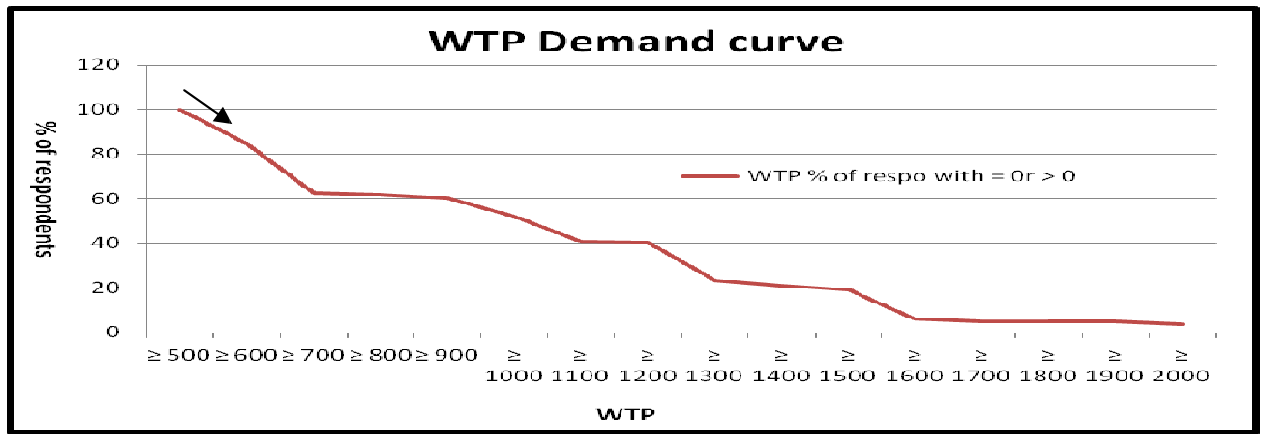

Figure 1: WTP curve 
Based on Figure 1, the total WTP can be calculated by the area under the curve:

Total WTP $=2,000$ ' $3.9+1,900$ ' $1.1+1,800^{\prime} 0+\ldots+600^{\prime} 22.7+500$ ' $14.5=99,234.92$ NRs

The average WTP was 548.26 NRs. But the demand curve shows there was a sharp decrease in the number of respondents who are willing to pay between 600 and 700 NRs. Therefore the highest amount that the respondents were willing to contribute was 600 .

\section{Conclusions}

The purpose of study was to assess the WTP by vehicle owners for carbon offsetting programs in an attempt to assist local government institutions and stakeholders take some important steps forward on environmental conservation. The statistical analyses revealed that educational level was a key factor contributing to WTP and thus, environmental conservation. In addition to educational level, occupation was another contributing factor. The results of this study clearly revealed the businessmen would be more willing to pay a higher amount of money for carbon offsetting programs.

The study only evaluated the WTP on an annual basis. Further studies should focus on fuel consumptions and emissions by different vehicles. Furthermore, the carbon sequestration of the community forest should be assessed for a more thorough understanding of the current situation.

To the best of our knowledge, this is the first study conducted in Nepal on the WTP for carbon offsetting programs. The results obtained in this study can stimulate other researchers to conduct further studies. The number of individuals who participated in this study was quite small. Therefore, these results might not be applicable for problem-solving and decisionmaking. However, this study might bring awareness to stakeholders including community forest user groups, municipalities, and district development committees, among others.

\section{References}

Angelsen, A., Streck, C., Peskett, L., Brown, J. and Luttrell, C. 2008. What is the right scale for REDD

Carson, R.T., Flores N.E. and Meade, N.F. 2001. Contingent valuation: Controversies and evidence. Environmental and Resource Economics, 19(2):173-210

$\mathrm{CO}_{2}$ emissions from fuel combustion: "CO emissions / population", Excel spreadsheet, in IEA 2012. (per person co2 emission 2.9 developing country and 10.4 developed country in 2010)

Doha amendment to the Kyoto Protocol to the United Nations Framework Convention on Climate Change Doha, 8 December 2012, http://unfccc.int/kyoto_protocol/doha_ amendment/items/7362.php 
Economicvaluation, contingent valuation, http://www.ecosystemvaluation.org/ contingent_valuation.htm

Karky, B.S. and Stutsch, M. 2010. The cost of carbon abatement through community forest management in Nepal Himalaya, Ecological Economics 69 (2010) 666-672.

Khanal, Y., Upadhyaya, C.P. and Sharma, R.P. 2008. Economic valuation of water supply service from two community forests in Palpa district. Ban ko Jankari Vol 20 No 1

Kulshreshtha, A. N., Lac, S., Johnston, M and Kinar, C. 2000. Carbon Sequestration in Protected Areas of Canada: An Economic Valuation, A research report. Department of AgriculturalEconomics, University of Saskatchewan, Saskatoon, Saskatchewan.

Pokhrel, A.R. 2009. Nepal Forestry outlook study, Asia-Pacific Forestry Sector Outlook StudyIIWorking Paper Series, Working Paper No. APFSOS II/WP/2009/05

Shrestha, N.K. 1998. Community forestry user group managerial innovation withroot, History of forest management in Nepal)

Tsang, F. and Burge, P. 2011. Paying for carbon emission reduction, RAND Corporation

Wertz-Kanounnikoff, S. and Verchot, L.V. With Kanninen, M. And Murdiyarso, D. 2008. Do we monitor, report and verify carbon emissions from forests

Whittington, D. 2002. "Improving the Performance of Contingent Valuation Studies in Developing Countries." Environmental \& Resource Economics, European Association of Environmental and Resource Economists. Vol. 22(1), pages 323-367, June. 